\title{
Oxidative Stress Plays an Important Role in Zoledronic Acid-Induced Autophagy
}

\author{
V. K. M. KHANDELWAL ${ }^{1,2,6}$, L. M. MITROFAN ${ }^{3}$, J. M. T. HYTTINEN ${ }^{4}$, \\ K. R. CHAUDHARI ${ }^{1}$, R. BUCCIONE ${ }^{2}$, K. KAARNIRANTA ${ }^{4,5}$, T. RAVINGEROVÁ ${ }^{6}$, \\ J. MÖNKKÖNEN ${ }^{1}$
}

${ }^{1}$ School of Pharmacy, University of Eastern Finland, Kuopio, Finland, ${ }^{2}$ Department of Translational Pharmacology, Consorzio Mario Negri Sud, Santa Maria Imbaro, Italy, ${ }^{3}$ INSERM U908 (JE-2488)

"Signalisation des facteurs de croissance dans le cancer du sein-Protéomique fonctionnelle", Université des Sciences et Technologies de Lille 1, Villeneuve d'Ascq, France, ${ }^{4}$ Department of Ophthalmology, Institute of Clinical Medicine, University of Eastern Finland, Kuopio, Finland, ${ }^{5}$ Department of Ophthalmology, Kuopio University Hospital, Kuopio, Finland, ${ }_{6}^{6}$ Institute for Heart Research, Slovak Academy of Sciences and Centre of Excellence of SAS, Bratislava, Slovakia

Received March 16, 2014

Accepted August 11, 2014

\section{Summary}

Several pre-clinical and clinical studies have demonstrated zoledronic acid (Zol), which regulates the mevalonate pathway, has efficient anti-cancer effects. Zol can also induce autophagy. The aim of this study is to add new understanding to the mechanism of autophagy induction by Zol. LC3B-II, the marker for autophagy was increased by Zol treatment in breast cancer cells. Autophagosomes induced by Zol were visualized and quantified in both transient (pDendra2-hLC3) and stable MCF-7GFP-LC3 cell lines. Acidic vesicular organelles were quantified using acridine orange. Zol induced a dose and time dependent autophagy. Treatment of Zol increased oxidative stress in MCF-7 cells, which was reversed by $\mathrm{GGOH}$ or anti-oxidants. On the other hand, treatment with $\mathrm{GGOH}$ or anti-oxidants resulted in decreased levels of LC3B-II. Further, the induced autophagy was irreversible, as the washout of Zol after $2 \mathrm{~h}$ or $24 \mathrm{~h}$ resulted in similar levels of autophagy, as induced by continuous treatment after $72 \mathrm{~h}$. Thus, it can be summarized that Zol can induce a dose dependent but irreversible autophagy, by its effect on the mevalonate pathway and oxidative stress. This study adds to the understanding of the mechanism of action of Zol, and that it can induce autophagy at clinically relevant shorter exposure times in cancer cells.

Key words

Dendra2 • GGOH • FOH • LC3B • Prenylation

\section{Corresponding author}

V. K. M. Khandelwal, Institute for Heart Research, Slovak Academy of Sciences and Centre of Excellence of SAS, Bratislava, Slovakia. Fax: +421 2 /54776637. E-mail: drvinothk@gmail.com

\section{Introduction}

Zol, the third generation nitrogen containing bisphosphonate (N-BP), is the first bisphosphonate to be approved in many countries for the treatment of cancerinduced bone disease from a variety of solid tumors and multiple myeloma (Ottewell et al. 2009, Green 2003). Zol consists of a heterocyclic imidazole moiety connected by a two-carbon side chain to the bisphosphonate P-C-P. Compared to other bisphosphonates, the prevailing structural feature provides more potent inhibitory activity on osteoclasts, without adversely affecting bone mineralization (Green et al. 1994, Dunford et al. 2001). Several pre-clinical and clinical studies have demonstrated that Zol has efficient anti-cancer effects (Green 2003, Thompson and Rogers 2007, Clézardin 2011). The importance of Zol is increasing as new properties are being reported, including its potential use to target bone metastasis (Chaudhari et al. 2012a, b). Zol (and other N-BPs) regulates the mevalonate pathway. It interferes primarily with farnesyl pyrophosphate synthase (FPPS) and geranylgeranyl pyrophosphate synthase 
(GGPPS) (Clézardin 2011, Guo et al. 2007, Goffinet et al. 2006, Coxon et al. 2000, Rogers et al. 2011, Mönkkönen et al. 2008). These enzymes are required for the formation of farnesyl pyrophosphate (FPP) and geranylgeranyl pyrophosphate (GGPP), respectively. FPP and GGPP are responsible for the prenylation of essential small signaling proteins (Rac, Ras, Rho, CDC42) (Guo et al. 2007, Thompson and Rogers 2007). In addition, we have previously shown that, as a consequence of inhibition of mevalonate pathway, Zol leads to the accumulation of isopentenyl pyrophosphate (IPP), which is converted to a cytotoxic ATP analogue (1-adenosin-5'yl ester 3-(3-methylbut-3-enyl) ester triphosphoric acid; ApppI), resulting in apoptosis (Mönkkönen et al. 2006, 2007, 2008, Räikkönen et al. 2009).

Recently, it was discovered that Zol can induce autophagy (Wasko et al. 2011, Lin et al. 2011). However, the mechanism of action behind the Zol-induced autophagy has not been explored. Therefore, we aim to investigate the mechanism involved in Zol-induced autophagy.

Autophagy, (derived from Greek meaning 'selfeating') characterized as a type of programmed cell death, is a highly regulated process, important in both physiological and pathological conditions (Eskelinen 2005, Zhuang et al. 2009). Autophagy is a complex collection of dynamic processes by which long-lived proteins, intracellular pathogens and cytoplasmic organelles, are sequestered in double-membrane-bound organelles. The sequestered material is then degraded and possibly recycled to generate macromolecules and ATP, to maintain cellular homeostasis (Shvets et al. 2008). Hence, autophagy is considered as both survival mechanism and a way of cell death, depending on the severity and stimuli inducing the autophagy (Levine and Klionsky 2004, Zhuang et al. 2009, Eskelinen 2005). In addition to the well known mechanisms involved in autophagy (phosphatidylinositol 3-kinase (PI3K)/Akt/ mammalian target of rapamycin), oxidative stress, hypoxia and ER stress are well known modulators (Scherz-Shouval et al. 2007, Pan et al. 2009, Hwang et al. 2010, Chen et al. 2008, He and Klionsky 2009). In this study, in addition to the confirmation of the Zolinduced autophagy, we also provide evidence for i) the role of oxidative stress in Zol-induced autophagy and ii) Zol-induced autophagy is irreversible and is effective at clinically relevant exposure times.

\section{Materials and Methods}

\section{Materials}

Zol [2-(imidazol-1-yl)-hydroxy-ethylidene-1, 1bisphosphonic acid, disodium salt, 4.75 hydrate (Mw 401.6)] was kindly provided by Novartis Pharma AG (Basel, Switzerland). A stock solution of Zol $(10 \mathrm{mM})$ was prepared in phosphate-buffered saline (PBS; pH 7.4; Invitrogen), filter-sterilized, and single use aliquots were stored at $-20^{\circ} \mathrm{C}$. The chemicals used were Farnesol (FOH) (Aldrich, F203), geranylgeraniol (GGOH) (Sigma, G3278), G 418 disulfate (Sigma, A1720), 2',7'-dichlorodihydrofluorescein diacetate (DCFDA) (Sigma, D6883), N-acetyl-L-cysteine (NAC) (Sigma, A9165), Tiron (Fluka, 89460), protease inhibitor cocktail (PI) (Sigma, P8340), phosphatase inhibitor cocktail 2 (ph.I) (Sigma, P5726), Bafilomycin (Baf) (LC Laboratories, B-1080), Hoechst 33342 (Molecular Probes, H3570) and Acridine orange (AO) (Molecular Probes, A1301). Stock solutions of GGOH and FOH were prepared in pure ethanol, whereas Baf in DMSO (Sigma). DCFDA was initially made in DMSO at $10 \mathrm{mM}$ and then sub stocked in PBS at $0.5 \mu \mathrm{M}$. Stock solutions of NAC and Tiron were prepared in PBS at $600 \mathrm{mM}$. Aliquots of single use were stored at $-20^{\circ} \mathrm{C}$. DCFDA was stored under argon gas. All compounds were diluted to the desired concentration immediately before use.

\section{Cell culture}

The human breast cancer cell line MCF-7 was obtained from the European Collection of Cell Cultures (Salisbury, UK). The stable MCF-7-eGFP-LC3 cells were kindly provided by M. Jäättelä (Institute of Cancer Biology, Copenhagen, Denmark). The cell lines were cultured in RPMI 1640 media with L-glutamine (BioWhittaker, Cambrex Bio Science, Belgium), supplemented with $10 \%$ fetal bovine serum, $100 \mathrm{Uml}^{-1}$ penicillin and $100 \mathrm{ggml}^{-1}$ streptomycin (Invitrogen,

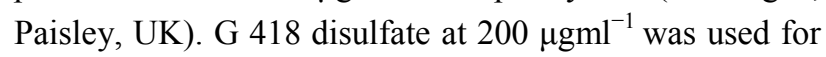
maintaining the stable cell lines. The cells were grown in a $5 \% \mathrm{CO}_{2}$ humidified incubator (MCO-18AIC (UV), Sanyo, Japan) at $37^{\circ} \mathrm{C}$. For assays, the cells were seeded at $2 \times 10^{5}$ cells per well of 8 -well ibiTreat microscopy chamber (Ibidi, Martisried, Germany), or $1.5 \times 10^{5}$ cells per well of 6-well plate, or $7.5 \times 10^{5}$ cells per $75 \mathrm{~cm}^{2}$ flasks (Nunc, Roskilde Denmark). After sufficient time for cell attachment $(24 \mathrm{~h})$, the media was replaced with fresh media containing respective treatment and incubated for 48 or $72 \mathrm{~h}$. 


\section{Western blotting}

Cells from $75 \mathrm{~cm}^{2}$ flasks (including the floating cells) were harvested and lysed using mammalian lysis buffer (Mammalian Cell Lysis kit, Sigma), containing $10 \mu \mathrm{lml}^{-1}$ of PI and ph.I each, and protein was isolated according to the manufacturer's instructions. The protein content was quantified using Bio-Rad Dc protein detection kit and equalized. The samples were diluted in 2X Laemmli buffer (125 mM Tris-HCl, $\mathrm{pH}$ 6.8, 4 \% SDS (w/v), $10 \%$ 2-mercaptoethanol, $20 \%$ glycerol (v/v), $0.004 \%$ bromphenol blue $\mathrm{w} / \mathrm{v}$ ) and heated for $5 \mathrm{~min}$ at $95{ }^{\circ} \mathrm{C}$. Proteins were separated in $12.5 \%$ or $10 \%$ SDSPAGE mini-gel or long gel, respectively, and electrotransferred onto polyvinylidene fluoride (PVDF) membranes (Amersham Biosciences Hybond-P PVDF membrane). A molecular weight marker (Full range rainbow, Amersham) was used as molecular weight control.

Unspecific binding sites on the PVDF membrane were blocked with $2 \%$ Amersham advanced blocking agent in Tris-buffered saline (TBS; $0.1 \%$ Tween 20, Sigma) for $1 \mathrm{~h}$ at room temperature. The following antibodies were used: mouse anti- $\beta$-actin (1:5000; Santa Cruz), rabbit anti-LC3B, Atg5, Atg7, raptor, rictor (1:2000), mTOR (1:6000), and anti-rabbit horse peroxidase (1: 10,000; HRP) conjugated secondary antibody (Cell Signaling Technology, Danvers, MA). The anti-mouse (1:10.000) HRP conjugated secondary antibody and immunodetection reagents were from Amersham Biosciences ${ }^{\mathrm{TM}} \mathrm{ECL}^{\mathrm{TM}}$ Western blotting detection reagents (GE Healthcare). The blots were developed on X-ray films, or scanned with ImageQuantRT ECL (Version 1.0.1, GE Healthcare) running under I Quant Capture-RT ECL software for Windows (Version 1.0.4.1, 1993-2006). Digitized pictures were adjusted and densitometric analysis was done using Quantity one software (version 4.6.9; basic; Biorad).

\section{Construction of pDendra2-hLC3 fusion plasmid}

Human microtubule-associated protein 1 light chain 3 (LC3-IA/B, GenBank no. AF303888) was amplified from DNase-treated (DNase I, Roche, Basel, Switzerland) total RNA extracted (Eurozol reagent, Euroclone, Wetherby, UK) from human ARPE-19 cells. Initially, mRNA was reverse-transcribed (MultiScribe reverse transcriptase, Applied Biosystems, Foster City, CA, USA), and LC3 open re-adding frame (ORF) was amplified with a high-fidelity DNA polymerase (Phusion Hot start DNA polymerase, Finnzymes, Espoo, Finland).
The following primers were used: sense 5'-ATA CTCGAG at ATG CCG TCG GAG AAG A and reverse 5'-TGT AAG CTT TTA CAC TGA CAA TTT CAT CCC. The restriction sites for XhoI and HindIII are in italics, respectively. The translation initiation and termination sites are in bold fonts. The additional bases enabling in-frame cloning are in minuscule.

The sticky ends for the amplified LC3 ORFs as well as for the multiple cloning site of the vector pDendra2-C (Evrogen, Moscow, Russia) (Gurskaya et al. 2006) were produced with above mentioned restriction endonucleases (MBI Fermentas, Vilnius, Lithuania). Ligated (T4 DNA Ligase, Roche, Basel, Switzerland) DNA forming a fusion gene of Dendra2 and human LC3 was transfected into competent DH5 $\alpha$ E. coli cells, which were prepared using the protocol of Inoue et al. (1990), cultured and purified (Sambrook et al. 1989). The integrity of the construct, denominated hereafter as pDendra2-hLC3, was determined initially by restriction endonuclease digestion analysis and finally sequencing the junction sites and the entire inserted LC3 ORF.

\section{Transient transfection}

MCF-7 cells were treated with Zol for $3 \mathrm{~h}$, and the transfection mixture was added to the media. $500 \mathrm{ng}$ of DNA per well of a 8-well ibiTreat microscopy chamber (final volume $200 \mu \mathrm{l}$ ) or $2.5 \mu \mathrm{g}$ DNA per well of a 6-well plate (final volume $1 \mathrm{ml}$ ), was transfected with Exgen500 in vitro transfection reagent (Fermentas), as per the manufacturer's instructions. After $24 \mathrm{~h}$, the used media is replaced with equilibrated complete media $(250 \mu \mathrm{l}$ or $2.5 \mathrm{ml})$ with respective treatments. At the end of $72 \mathrm{~h}$ of Zol exposure, the 8-well slides were used for confocal imaging.

\section{Confocal imaging}

The fluorescent images were obtained with a Zeiss Axio Observer inverted microscope $(20 \mathrm{x}$, or $63 \mathrm{x}$ NA 1.4 oil - objectives) equipped with Zeiss LSM 700 confocal module (Carl Zeiss Microimaging GmbH, Jena, Germany). For living cell imaging, Zeiss XL-LSM S1 incubator with temperature and $\mathrm{CO}_{2}$ control was used. ZEN 2009 software (Carl Zeiss) was used for image processing.

Autophagy was quantified by counting the average number of eGFP-LC3 or Dendra2-LC3 green puncta per cell in control and Zol100 cells; $n=3$ experiments, 40-50 cells per condition per experiment. 


\section{Flow cytometry analysis}

For flow cytometry analysis, MCF-7 cells were seeded in 6-well plates. After treatment, both floating and attached cells were harvested, $2 \mathrm{x}$ washed with PBS, and pellets were collected in $12 \times 75-\mathrm{mm}$ polystyrene $5 \mathrm{ml}$ test tubes (BD Falcon ${ }^{\mathrm{TM}}$ tubes). The cells were resuspended in $250 \mu \mathrm{l}$ PBS, stained and analyzed with FACSCanto Flow Cytometer (FACS; BD, San Jose, CA, USA) running under BD FACSDiva ${ }^{\mathrm{TM}}$ software. At least 10,000 events were recorded per sample. The samples were kept on ice starting from harvesting until analyzed, unless specified.

Autophagy is characterized by increased formation of acidic vesicular organelles (AVOs) (autophagolysosomes, lysosomes and late endosomes) (Chen et al. 2008, Klionsky et al. 2008, Paglin et al. 2001). AVOs were quantified by flow cytometry after staining the cells with AO. AO is a weak base that accumulates in acidic spaces and fluoresces bright red. The AVOs can be quantified based on the fact that the increase in intensity of the red fluorescence is proportional to the degree of acidity. After Zol treatment, the cells were re-suspended in $250 \mu \mathrm{l}$ PBS, stained with $\mathrm{AO}\left(1 \mu \mathrm{gml}^{-1}\right)$ for $15 \mathrm{~min}$ at $37^{\circ} \mathrm{C}$ and analyzed on the FACS.

Cellular oxidative stress was monitored using DCFDA, a sensitive cell-permeable probe. DCFDA, when internalized, is hydrolyzed by cellular esterases to $2^{\prime}, 7^{\prime}$-dichlorodihydrofluorescein. It is then oxidized to the fluorescent $2^{\prime}, 7^{\prime}$-dichlorofluorescein (DCF) by a broad range of oxidizing reactions during intracellular oxidant stress, primarily by hydrogen peroxide or low molecular weight peroxides. DCF remains in the cell, and the green fluorescence intensity is proportional to the amount of oxidative stress produced in the cells, which was quantified using FACS (Brubacher and Bols 2001, Cossarizza et al. 2009). For intracellular ROS measurement, cells were harvested and incubated with $5 \mu \mathrm{M}$ of DCFDA in the dark, at $37^{\circ} \mathrm{C}$ for $20 \mathrm{~min}$. The cells were analyzed by flow cytometry.

\section{Statistics}

Data were expressed as the mean value \pm S.E. and analyzed by one-way analysis of variance or t-test, with the Bonferroni post-test using GraphPad Prism (San Diego, CA) version 5.0 for Windows; $\mathrm{p}<0.05$ was considered significant.
A

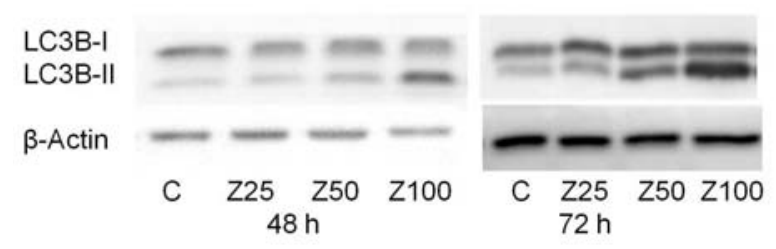

C

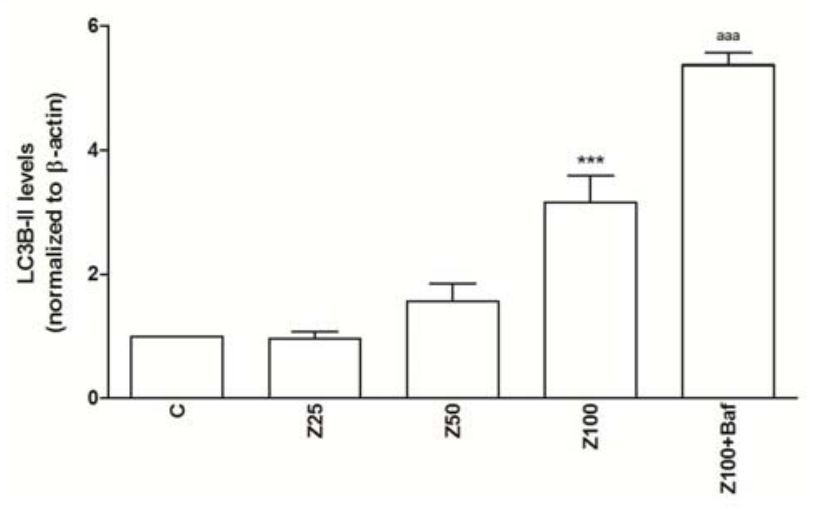

B

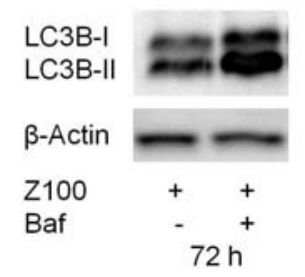

Fig. 1. Zol treatment increases the formation of LC3B-II. [A] Western blots showing LC3B-II levels from MCF-7 cells treated with different concentrations of Zol (Z25, Z50 and Z100 represents $25 \mu \mathrm{M}, 50 \mu \mathrm{M}$ and $100 \mu \mathrm{M}$ respectively) for $48 \mathrm{~h}$ and 72 h. [B] Baf (500 nM) was added to the media $4 \mathrm{~h}$ before the end of the $72 \mathrm{~h}$ of $\mathrm{Z} 100$ exposure. [C] Densitometric quantification of protein levels of LC3B-II at $72 \mathrm{~h}$ treatment, normalized to $\beta$-actin, and relative to $C$, which was set to $1 . Z 25, Z 50$ and $\mathrm{Z} 100$ at $72 \mathrm{~h}$ were compared with $\mathrm{C}$, while Z100+Baf, Z100+GGOH and $\mathrm{Z} 100+\mathrm{FOH}$ were compared with $\mathrm{Z} 100$ at 72 h. $* * * \mathrm{p}<0.001$ vs. C; aaa $p<0.001$ vs. $Z 100 ; n=5-8$

\section{Results}

Zoledronic acid induces dose dependent autophagy in breast cancer cells

Autophagy is a complex multistep dynamic process and needs to be characterized at various stages and different methods. (i) During the formation of double membraned autophagosomes, LC3-II (the specific marker identified to be associated with autophagic vesicles) is localized after phosphatidylethanolamine-modification of LC3-I. Here we studied this conversion using western blotting and (ii) the formed autophagosomes were 
visualized in both transient (pDendra2-hLC3) and stable MCF-7-GFP-LC3 cells and (iii) quantified using confocal microscopy. At a later stage the autophagosomes fuse with lysosomes to form autophagolysosomes, (iv) hence the increased formation of acidic vesicles was monitored using AO staining. (v) Increased turnover of autophagy vesicles (flux) was studied using the end-stage autophagy inhibitor Baf.
Dendra2

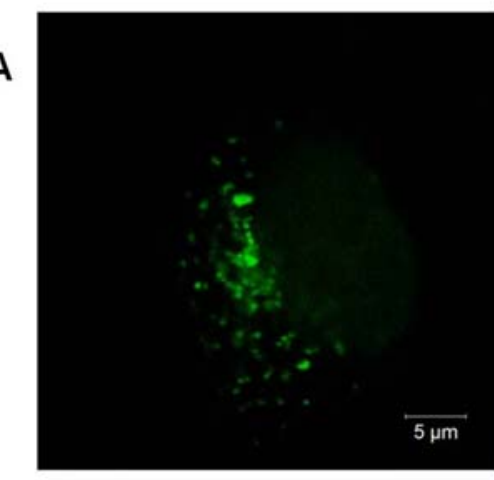

C

B

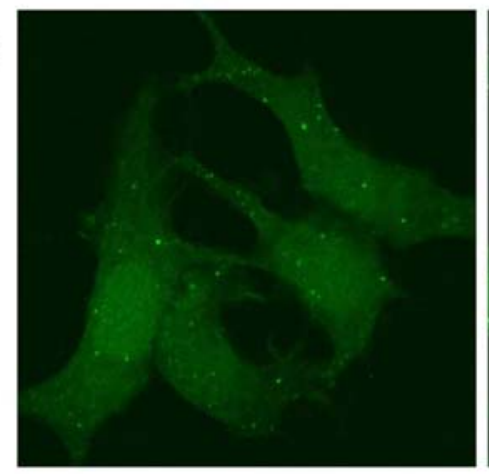

Hoechst

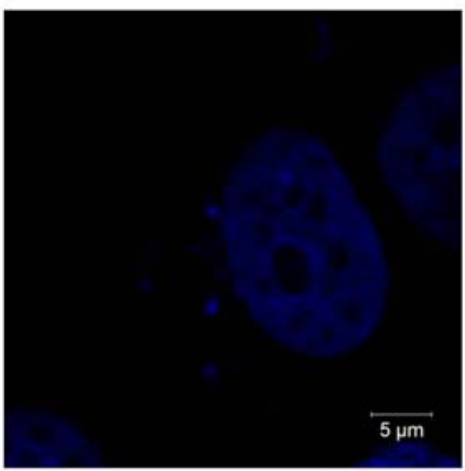

Z100

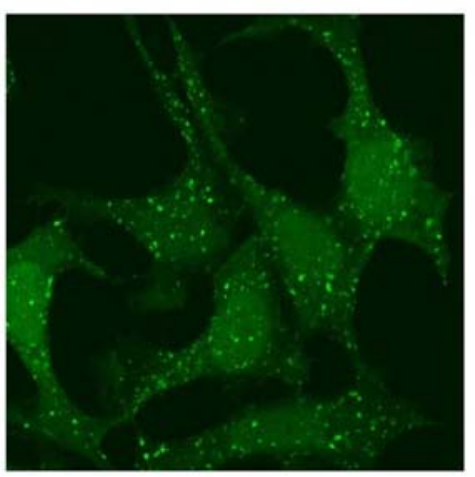

Merge
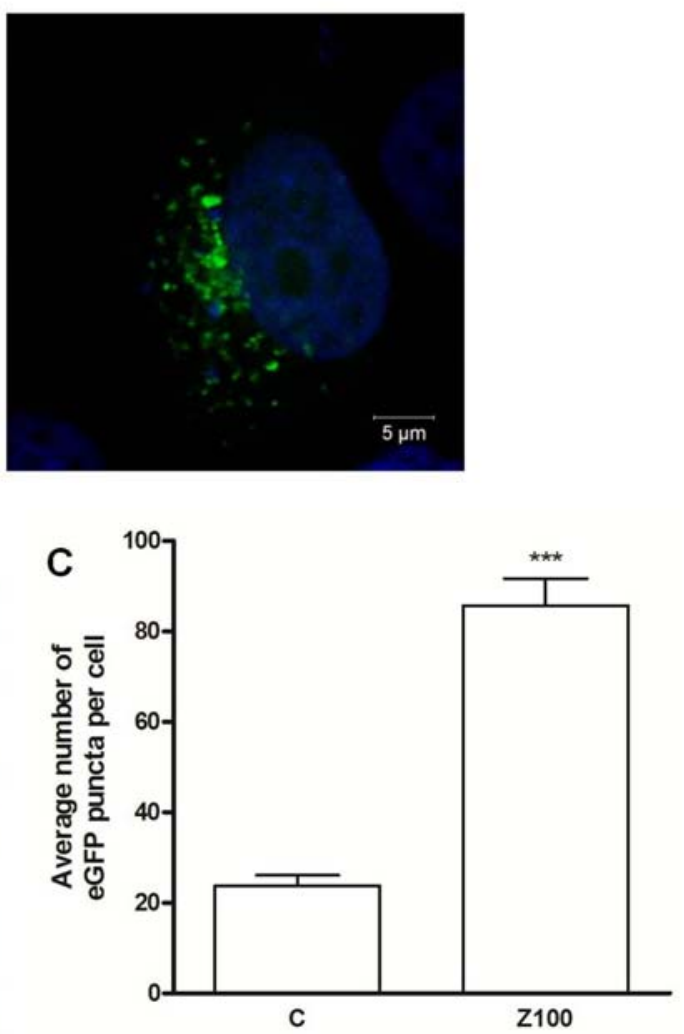

Fig. 2. Zol increases the formation of autophagosomes. [A] Confocal images of transiently transfected MCF-7 cells (with pDendra2hLC3) treated with Z100 for $72 \mathrm{~h}$. A single cell at higher resolution clearly displays the LC3 punctas as an indicator of the autophagic vesicles. [B] Confocal images depicting the increase in number of eGFP puncta on treatment with Z100 in stable MCF-7-eGFP-LC3 cells, compared to C. [C] Quantification of average number of eGFP-LC3 puncta per cell in control and Z100 treated stable MCF-7-eGFP-LC3 cells. $\mathrm{n}=3$ experiments, $40-50$ cells per condition per experiment. $* * * \mathrm{p}<0.001$ vs. $\mathrm{C}$

The conversion of LC3B-I to LC3B-II was evident at $48 \mathrm{~h}$ and was significant $(\mathrm{p}<0.01)$ at $72 \mathrm{~h}$ of $100 \mu \mathrm{M}$ Zol treatment, analyzed by western blotting (Fig. 1A,C). Further, LC3B-II was significantly increased when Baf was added $4 \mathrm{~h}$ before the end of $72 \mathrm{~h}$ of $\mathrm{Zol}$ treatment, confirming the Zol induced higher levels of LC3B-II is due to induction of autophagy (Fig. 1B,C). On treatment with Zol, both the transient (pDendra2-hLC3) and stable (MCF-7-GFP-LC3) cells displayed autophagy vesicles identified as green puncta in the cytoplasm (Fig. 2A,B). Interestingly, there was a significant increase in number of eGFP puncta $(p<0.001$; Fig. $2 \mathrm{C})$ and Dendra2 puncta ( $<<0.01$; supplementary Fig. S1) per cell with Z100 treatment. Dendra2 is a monomeric green fluorescent protein, which displays enhanced brightness and an accelerated maturation rate at $37^{\circ} \mathrm{C}$. The supplementary Figure S2 demonstrates how cells shift due to change in acidic vesicles. When treated with Z100, the cells had increased number and/or acidity of the acidic vesicles (which results in higher red fluorescence), and shift into the gate (AVO). In presence of Baf $(500 \mathrm{nM})$, which increases the $\mathrm{pH}$ of the acidic vesicles (decrease in red fluorescence), the cells shift back. X-axis represents the red channel (PerCP-Cy5.5), while the Yaxis represents the green channel (FITC). The percentage of cells with increased acidic vesicles was concentration and time-dependently increased in Zol-treated cells (Fig. 3). 


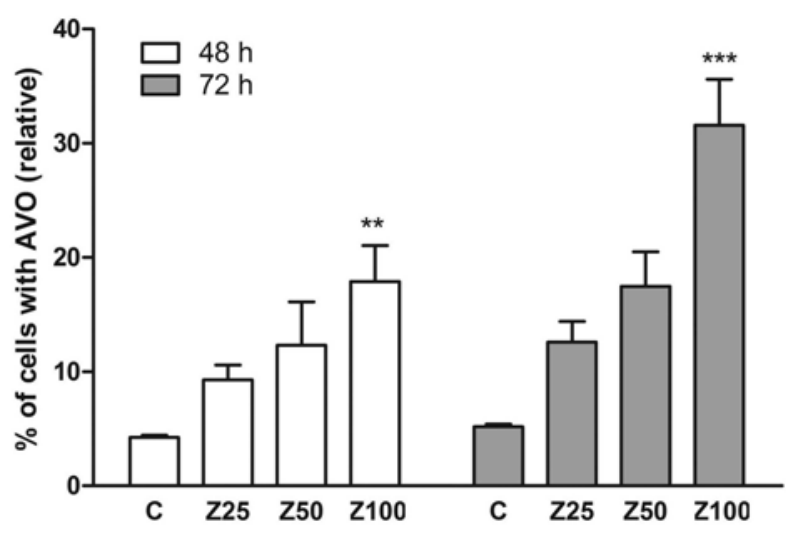

Fig. 3. Zol induces acidic vesicular organelles. MCF-7 cells treated with different concentrations of Zol for $48 \mathrm{~h}(\mathrm{n}=2-4)$ and $72 \mathrm{~h}(\mathrm{n}=4-7)$ were stained with $\mathrm{AO}$ and the percentage of cells with relative increase in acidic vesicles were measured. $* * \mathrm{p}<0.01 ; * * * \mathrm{p}<0.01$ vs. $\mathrm{C}$ of respective time points

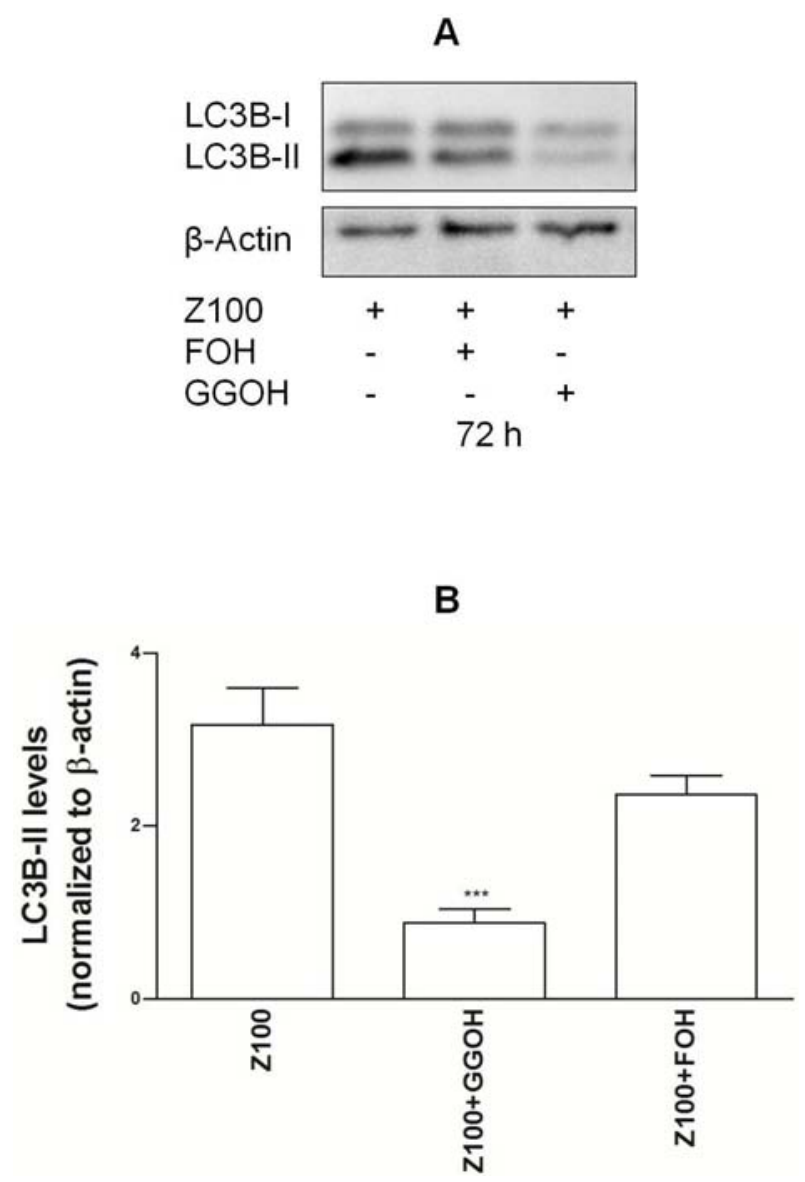

Fig. 4. $[$ A] Western blots showing LC3B-II levels from MCF-7 cells treated with $\mathrm{Z100}$ with or without $\mathrm{FOH}(25 \mu \mathrm{M})$, or $\mathrm{GGOH}$ $(25 \mu \mathrm{M})$ for $72 \mathrm{~h}$. [B] Densitometric quantification of protein levels of LC3B-II at $72 \mathrm{~h}$ treatment, normalized to $\beta$-actin. $* * * \mathrm{p}<0.001$ vs. $\mathrm{Z} 100 ; \mathrm{n}=5-8$

Effect of Zol on autophagy was dependent on its effect on mevalonate pathway

Zol exerts its effect by interfering with FPPS and GGPPS (Clézardin 2011, Guo et al. 2007, Goffinet et al.
2006, Rogers et al. 2011). The effect of GGOH and FOH on Zol-induced autophagy was tested. GGOH and FOH are cell permeable isoprenoid lipid substrates that are converted to intermediates (GGPP and FPP) of the mevalonate pathway (Mitrofan et al. 2009, Moriceau et al. 2010). On exposure of $\mathrm{Zol}(100 \mu \mathrm{M}$ for $72 \mathrm{~h})$, MCF-7 cells showed a strong autophagy induction, which was rescued by GGOH ( $<<0.001$; Fig. 4A,B). FOH showed a partial reduction of LC3B-II levels.

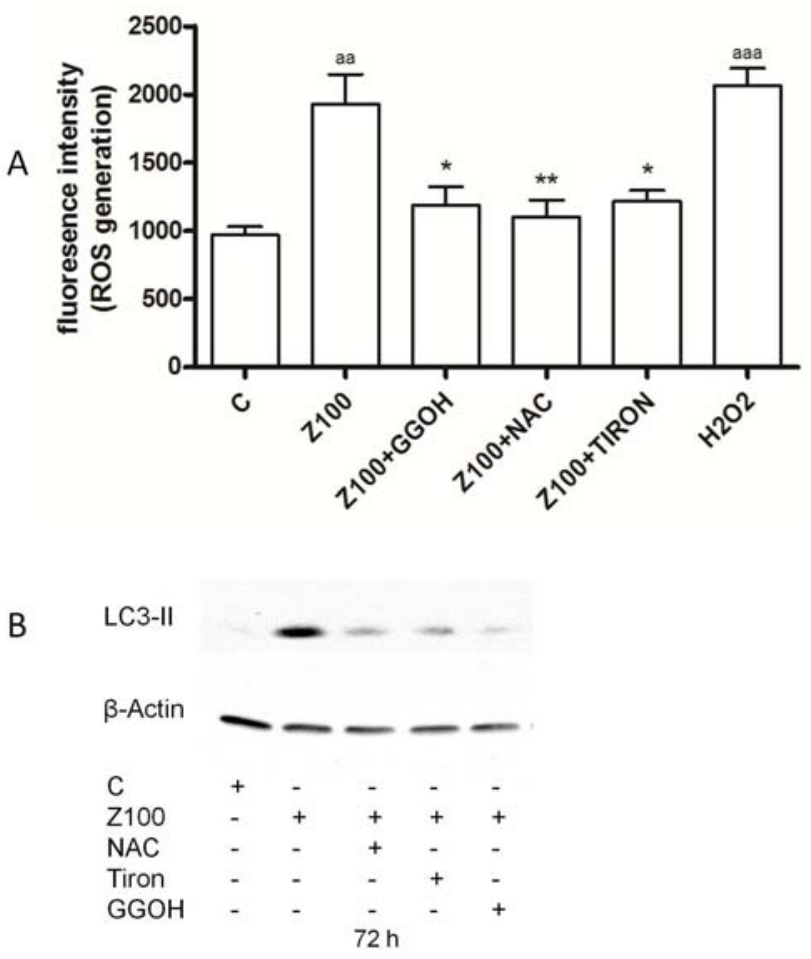

Fig. 5. Role of oxidative stress in Zol-induced autophagy. [A] Flow cytometry measurement of ROS, in MCF-7 cells treated with Z100, Z100+GGOH $(25 \mu \mathrm{M}), \mathrm{Z100+NAC}(2 \mathrm{mM})$, Z100+Tiron ( $2 \mathrm{mM})$ for $72 \mathrm{~h}$, or $\mathrm{H}_{2} \mathrm{O}_{2}(0.5 \mathrm{mM})$ for $6 \mathrm{~h}$, using the stain DCFDA $(n=4)$. At least 10,000 events were recorded per sample. ${ }^{*} p<0.05$, ${ }^{* *} p<0.01$ vs. $Z 100 ;{ }^{\text {aa }} p<0.01 ;{ }^{\text {aaa }} p<0.001$ vs. C. [B] Western blots showing LC3B-II protein levels from MCF-7 cells. NAC $(2 \mathrm{mM})$, or Tiron $(2 \mathrm{mM})$, or $\mathrm{GGOH}(25 \mu \mathrm{M})$ was treated with or without $\mathrm{Z} 100$ for $72 \mathrm{~h}$.

Zol-induced autophagy was mediated by oxidative stress Oxidative stress due to higher levels of ROS has been shown to be one of the important autophagy inducers (Scherz-Shouval et al. 2007, Chen et al. 2008, Hwang et al. 2010). Recently, both experimental and clinical studies have shown Zol treatment resulted in increased oxidative stress (Bagan et al. 2014, Koçer et al. 2013). Thus, we examined whether ROS was increased in MCF-7 cells by Zol, using DCFDA as a probe in FACS. Though there was some evidence of ROS generation at 
$48 \mathrm{~h}$ of $\mathrm{Z} 100$ treatment, oxidative stress reached significant $(\mathrm{p}<0.01)$ levels at $72 \mathrm{~h}$ of treatment (supplementary Fig. S3). To confirm if the mechanism of action of Zol involves ROS production, further studies were carried out in MCF-7 cells. It was interesting to note that, Zol when treated along with GGOH or antioxidants NAC or Tiron $(2 \mathrm{mM})$, the ROS levels were significantly decreased (Fig. 5A). $\mathrm{Zol}$ and $\mathrm{H}_{2} \mathrm{O}_{2}$ treatment resulted in significant rise in ROS levels, compared to $\mathrm{C}$.

When Z100 was treated with or without NAC and Tiron, surprisingly both the antioxidants were able to reduce the Zol-induced LC3B-II protein levels, which is evident from Figure 5B. This elucidates the involvement of oxidative stress in Zol-induced autophagy. On the other hand, $\mathrm{H}_{2} \mathrm{O}_{2}$ treatment for $6 \mathrm{~h}$ induced autophagy in MCF-7 cells. Further, the LC3-II levels were unaffected by the vehicles used (supplementary Fig. S4).

\section{LC3-II}

$\beta$-Actin

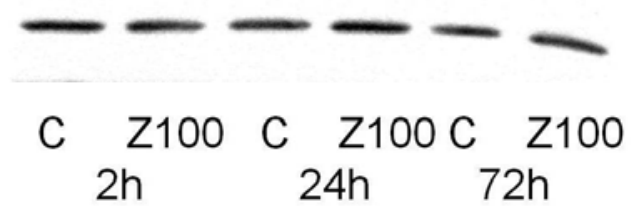

Fig. 6. Zol induces irreversible autophagy. Western blot showing LC3B-II protein levels from MCF-7 cells treated with Z100. In case of $2 \mathrm{~h}$ or $24 \mathrm{~h}$, the culture medium was replaced with fresh medium without Zol, and evaluated for LC3-II levels at the end of $72 \mathrm{~h}$. The $72 \mathrm{~h}$ sample was after continuous treatment of Z100 for $72 \mathrm{~h}$; C represents the respective controls.

\section{Zol-induced autophagy is irreversible}

In accordance with the previous reports, we confirm that Zol-induced autophagy occurs at $72 \mathrm{~h}$ of exposure. But, clinically the plasma half-life of Zol is less than $4 \mathrm{~h}$ (Green 2003), hence it would be difficult to exploit this interesting activity of Zol for the betterment of the patients. To combat this, we tested other alternatives of short duration of exposure. Zol was treated for $2 \mathrm{~h}$ or $24 \mathrm{~h}$ and the culture medium was replaced with fresh medium without Zol, and evaluated for LC3-II levels at the end of 72 h. Again, it was remarkable to observe that at both the lower exposure times $2 \mathrm{~h}$ and $24 \mathrm{~h}$, Zol was able to induce similar levels of LC3-II, as compared to $72 \mathrm{~h}$ of continuous treatment (Fig. 6). Hence, Zol-induced autophagy is irreversible and clinically relevant.

\section{Discussion}

Autophagy is a complicated, dynamic, multistage catabolic process, where long-lived proteins and cytoplasmic organelles are sequestered by doublemembrane vesicles (autophagosomes), which fuse with lysosomes to form degradative compartments (autophagolysosome). When the degradation is complete, it becomes a residual body (telolysosome), which might be subsequently recycled by the cell (Shvets et al. 2008, Klionsky et al. 2008). Autophagy has to be evaluated at various stages to prove it is being modulated. An extensive review on guidelines for the use and interpretation of assays for monitoring autophagy is available (Klionsky et al. 2008). LC3 (mammalian homologue of Atg8) is a crucial marker protein for autophagy vacuoles (Klionsky et al. 2008, Mizushima and Yoshimori 2007). During the formation of autophagosomes, cytosolic LC3B-I is conjugated with phosphatidylethanolamine at their C-terminus to form LC3B-II. This lipidated form remains associated with the autophagosome membranes (Shvets et al. 2008). Hence, an increase in LC3B-II denotes the presence of autophagy, which was observed when MCF-7 cells were treated with Zol for up to $72 \mathrm{~h}$. A point of caution is that, the LC3B-II is found both inside and outside the walls of the autophagosomes. The inner LC3BII is degraded in the autophagolysosome stage. The degradation of LC3B-II can be prevented by drugs which alter lysosomal $\mathrm{pH}$, like Baf (a vacuolar-type $\mathrm{H}^{+}$-ATPase inhibitor), which is also known to inhibit autophagosomelysosome fusion (Mizushima and Yoshimori 2007, Yamamoto et al. 1998, Klionsky et al. 2008). Hence, both autophagy inducers and inhibitors (end stage) can increase total LC3B-II. To distinguish between an inducer and an inhibitor, autophagic flux was tested, taking the benefit of the fact that LC3B-II is increased in the presence of end stage autophagy inhibitors (Baf) (Mizushima and Yoshimori 2007). Towards the end of the Zol treatment, addition of Baf (for $4 \mathrm{~h}$ ), resulted in a further increase of LC3B-II levels, evident from Figure 1B,C. This suggests that Zol has an autophagy inducing effect. On the other hand, if Zol was an autophagy inhibitor, the end stage blocking would have not resulted in a further increase in LC3B-II levels. Autophagy is also characterized by an increase in the number of AVOs, and was observed in MCF-7 cells treated with Zol, the outcome was is in line with previous studies using similar strategy (Yamamoto et al. 1998, Takeuchi et al. 2005, Chen et al. 2008, Paglin et al. 2001). 
Since the autophagy was maximally induced at Z100 when treated for $72 \mathrm{~h}$, some of the observations were conducted only at this time point and concentration. The action of Zol on autophagy was related to its inhibitory effect on protein prenylation, especially geranylgeranylation and to some extends on farnesylation. This is in accordance with many other studies which explain that the biological activities of Zol are mediated mainly by the inhibition of geranylgeranylation, though its primary effect is to inhibit FPPS (Rogers et al. 2011). The effect of Zol and N-BPs on apoptosis, proliferation, etc., has been shown to be rescued by $\mathrm{GGOH}$, in different cell types (Sonnemann et al. 2007, Mitrofan et al. 2009, 2010, Jagdev et al. 2001, Coxon et al. 2000, Goffinet et al. 2006). Previously, we showed that the protective effect of GGOH against Zol could at least in part be explained by its capacity to inhibit IPP/ApppI formation (Mitrofan et al. 2009, 2010). This mechanism acts in concert with the inhibition of accumulation of unprenylated proteins (Rogers et al. 2011).

In accordance with other observations (Bagan et al. 2014, Koçer et al. 2013), we also observed Zolinduced oxidative stress. Treatment of Zol (100 $\mu \mathrm{M}$ for $72 \mathrm{~h}$ ) resulted in increased oxidative stress in MCF-7 cells, which was reversed by GGOH or antioxidants. Further, the co-treatment of Zol and antioxidants resulted in reduced levels of LC3-II. In addition, treatment of MCF-7 cells with $\mathrm{H}_{2} \mathrm{O}_{2}$ resulted in increased oxidative stress and LC3-II levels. Hence it can be confirmed that oxidative stress played an important role in Zol-induced autophagy. Oxidative stress has been associated with the induction of autophagy in various studies (ScherzShouval et al. 2007, Chen et al. 2008, Hwang et al. 2010). Hence, this might be one of the possible mechanisms underlying induction of autophagy by Zol. It can be postulated that the inhibition of protein prenylation or accumulation of IPP/ApppI in the cells could induce oxidative stress, which could mediate some effects of Zol. It was reported that Zol can induce both autophagic and apoptotic cell death in prostate cancer cells (Lin et al. 2011). Hence, we cannot exclude the potential role of ROS in Zol-induced apoptosis. Here we elucidate the role of Zol-induced ROS on autophagy. Furthermore, it was found that Zol does not alter other protein levels known to modulate autophagy, Atg5, Atg7, mTOR, rictor and raptor (supplementary Fig. S5).

It is now clear that Zol can persistently induce autophagy in many cancer cell lines including MCF-7,
MDA-MB-231, PC3, DU145, CWR22Rv1 and LNCaP cells, as revealed in this and other studies (Wasko et al. 2011, Lin et al. 2011). The effect of Zol differs among cell lines, for different reasons, including the levels of IPP/ApppI which vary between cell lines (Mitrofan et al. 2009). Hence, further studies might be of interest to check if IPP/ApppI levels can affect autophagy. The dose and exposure time of Zol (Z100 for $72 \mathrm{~h}$ ) needed to induce autophagy is comparatively higher than plasma concentration that can be achieved clinically for treatment of breast cancer. Though at initial hours of clinical treatment the concentration could be theoretically reached, Zol is vigorously up taken by bone and the plasma concentration drops within few hours of administration (Green 2003). Hence, the higher concentration and duration may be achieved at the bone, and Zol can affect and induce autophagy in cancer cells which have metastasized to bone. Furthermore, for the first time, we have also demonstrated that the Zolinduced autophagy could be relevant at clinical exposure times. Previously, it has been shown, after a short pulse treatment of Zol, Zol and its metabolites were accumulated in the cells and were detected upto several hours (Räikkönen et al. 2009). This makes the short pulse treatment equivalent to long-term continuous treatment. The reported study utilized $25 \mu \mathrm{M}$ Zol treated for $1 \mathrm{~h}$ and observed up to $48 \mathrm{~h}$. However, in our study we utilized $\mathrm{Z} 100$ pulse treated for 2 or $24 \mathrm{~h}$, hence it can be expected that the accumulation of Zol and/or its metabolites would remain in the cells for more than $72 \mathrm{~h}$. The higher concentration (Z100) remains a concern, but if carefully observed Z25 and Z50 were able to induce some level of both autophagy and oxidative stress (though not significant) at $72 \mathrm{~h}$. Since, the effect of Zol was irreversible, it could be extrapolated, that at lower concentration, with longer duration, Zol might induce autophagy in cancer cells, which could be achieved in clinical practice.

\section{Conclusion}

Several pre-clinical and clinical studies have demonstrated that Zol, which regulates the mevalonate pathway, has efficient anti-cancer effects. Many drugs inhibiting post-translational prenylation by interfering with one or more enzymes of the mevalonate pathway, are known to regulate autophagy. Effect of Zol on autophagy was studied in detail at various stages of autophagy. Zol was able to increase the LC3B-II levels, 
LC3B flux, acidic vesicles, and autophagosomes (puncta of eGFP and pDendra2-hLC3), indicating the induction of autophagy. Oxidative stress was observed to be increased. GGOH or antioxidants decreased Zol-induced LC3B-II protein levels and oxidative stress. Hence, Zol can induce autophagy by its effect on the mevalonate pathway and oxidative stress in MCF-7 cells (Fig. 7). This study adds to the understanding of mechanism of action of Zol, which is being studied to treat diseases where autophagy is also involved, such as Paget's disease, cancer, parasitic infections, etc. (Ju and Weihl 2010, Sonnemann et al. 2007, Vesa et al. 2009). However, more studies are needed to further elaborate the role of inhibition of prenylation in oxidative stress and Zol-induced autophagy in vivo.

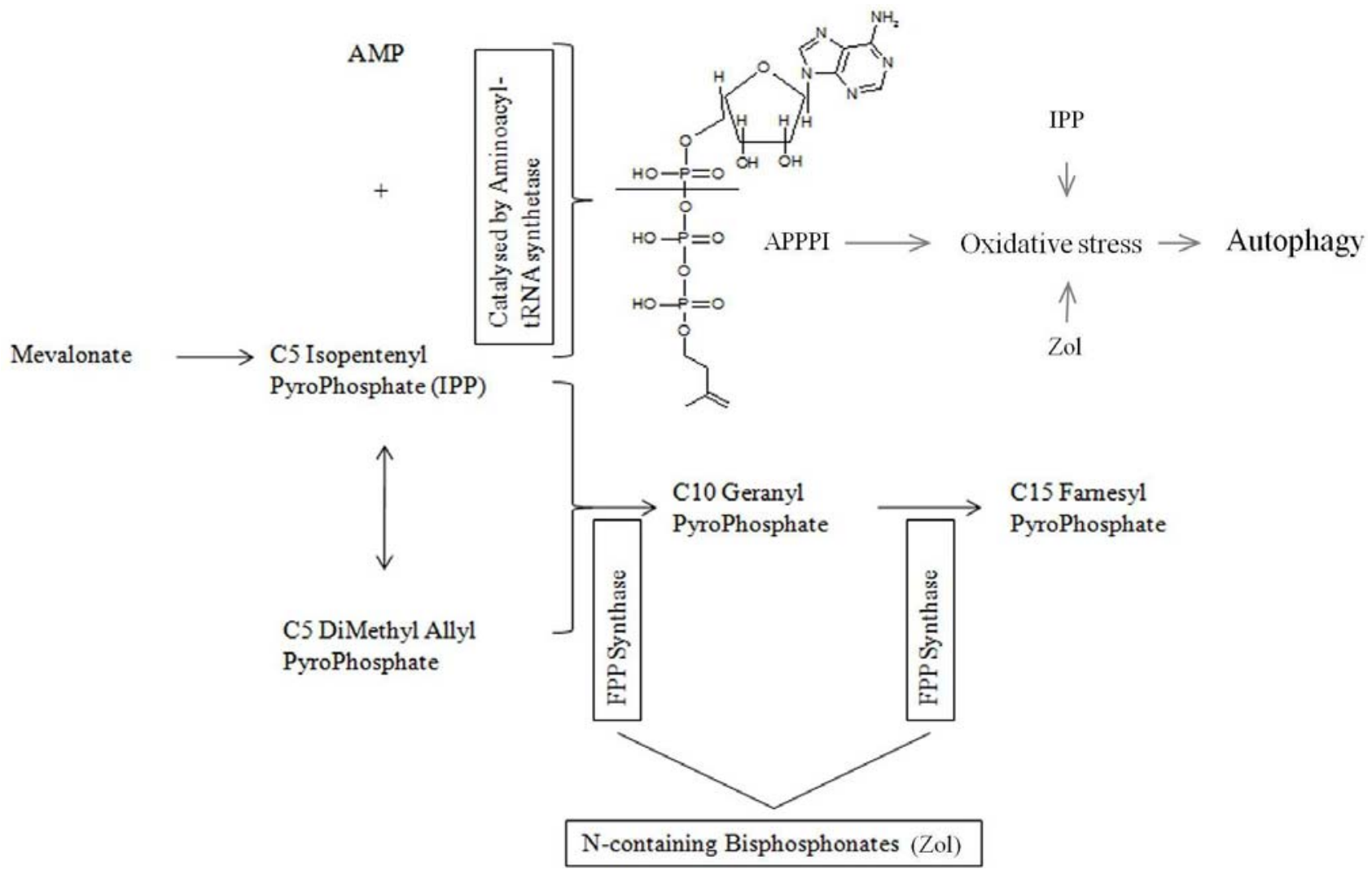

Fig. 7. Schematic representation of the possible mechanism of action of Zol-induced autophagy. Zol induces the formation IPP and ApppI, by inhibiting the mevalonate pathway. Zol in addition to IPP and ApppI accumulates in the cells and increases oxidative stress, resulting in autophagy.

\section{Conflict of Interest}

The funding body did not influence any outcome of the study. There is no conflict of interest.

\section{Acknowledgements}

This work was supported by NOVARTIS AG, Basle, Switzerland. We thank Anssi Nieminen, Kirsi Rilla, Lea Pirskanen, Hannu Mönkkönen and Nicola Martelli for their help in different aspects of the study.

\section{Abbreviations}

AO, acridine orange; AVO, acidic vesicular organelles; Baf, bafilomycin (Baf); DCFDA, 2',7'dichlorodihydrofluorescein diacetate; FACS, flow cytometer; FOH, farnesol; FPPS, farnesyl pyrophosphate synthase; GGOH, geranylgeraniol; GGPPS, geranylgeranyl pyrophosphate synthase; NAC, N-acetylL-cysteine; ph.I, phosphatase inhibitor cocktail; PI, protease inhibitor cocktail; Zol, zoledronic acid 


\section{References}

BAGAN J, SÁEZ GT, TORMOS MC, GAVALDA-ESTEVE C, BAGAN L, LEOPOLDO-RODADO M, CALVO J, CAMPS C: Oxidative stress in bisphosphonate-related osteonecrosis of the jaws. J Oral Pathol Med 43: 371$377,2014$.

BRUBACHER JL, BOLS NC: Chemically de-acetylated 2',7'-dichlorodihydrofluorescein diacetate as a probe of respiratory burst activity in mononuclear phagocytes. J Immunol Methods 251: 81-91, 2001.

CHAUDHARI KR, KUMAR A, KHANDELWAL VKM, MISHRA AK, MONKKONEN J, MURTHY RSR: Targeting efficiency and biodistribution of zoledronate conjugated docetaxel loaded pegylated PBCA nanoparticles for bone metastasis. Adv Funct Mater 22: 4101-4114, 2012a.

CHAUDHARI KR, KUMAR A, KHANDELWAL VKM, UKAWALA M, MANJAPPA AS, MISHRA AK, MONKKONEN J, RAMACHANDRA MURTHY RS: Bone metastasis targeting: a novel approach to reach bone using zoledronate anchored PLGA nanoparticle as carrier system loaded with docetaxel. $J$ Control Release 158: 470-478, 2012b.

CHEN Y, MCMILLAN-WARD E, KONG J, ISRAELS SJ, GIBSON SB: Oxidative stress induces autophagic cell death independent of apoptosis in transformed and cancer cells. Cell Death Differ 15: 171-182, 2008.

CLÉZARDIN P: Bisphosphonates' antitumor activity: an unravelled side of a multifaceted drug class. Bone 48: 71-79, 2011.

COSSARIZZA A, FERRARESI R, TROIANO L, ROAT E, GIBELLINI L, BERTONCELLI L, NASI M, PINTI M: Simultaneous analysis of reactive oxygen species and reduced glutathione content in living cells by polychromatic flow cytometry. Nat Protocols 4: 1790-1797, 2009.

COXON FP, HELFRICH MH, VAN'T HOF R, SEBTI S, RALSTON SH, HAMILTON A, ROGERS MJ: Protein geranylgeranylation is required for osteoclast formation, function, and survival: inhibition by bisphosphonates and GGTI-298. J Bone Miner Res 15: 1467-1476, 2000.

DUNFORD JE, THOMPSON K, COXON FP, LUCKMAN SP, HAHN FM, POULTER CD, EBETINO FH, ROGERS MJ: Structure-activity relationships for inhibition of farnesyl diphosphate synthase in vitro and inhibition of bone resorption in vivo by nitrogen-containing bisphosphonates. Pharmacol Exp Ther 296: 235-242, 2001.

ESKELINEN EL: Doctor Jekyll and Mister Hyde: autophagy can promote both cell survival and cell death. Cell Death Differ 12 (Suppl 2): 1468-1472, 2005.

GOFFINET M, THOULOUZAN M, PRADINES A, LAJOIE-MAZENC I, WEINBAUM C, FAYE JC, SERONIEVIVIEN S: Zoledronic acid treatment impairs protein geranyl-geranylation for biological effects in prostatic cells. BMC Cancer 6: 60, 2006.

GREEN JR: Antitumor effects of bisphosphonates. Cancer 97 (3 Suppl): 840-847, 2003.

GREEN JR, MÜLLER K, JAEGGI KA: Preclinical pharmacology of CGP 42'446, a new, potent, heterocyclic bisphosphonate compound. J Bone Miner Res 9: 745-751, 1994.

GUO RT, CAO R, LIANG PH, KO TP, CHANG TH, HUDOCK MP, JENG WY, CHEN CKM, ZHANG Y, SONG Y, KUO CJ, YIN F, OLDFIELD E, WANG AHJ: Bisphosphonates target multiple sites in both cis- and transprenyltransferases. Proc Natl Acad Sci USA 104: 10022-10027, 2007.

GURSKAYA NG, VERKHUSHA VV, SHCHEGLOV AS, STAROVEROV DB, CHEPURNYKH TV, FRADKOV AF, LUKYANOV S, LUKYANOV KA: Engineering of a monomeric green-to-red photoactivatable fluorescent protein induced by blue light. Nat Biotech 24: 461-465, 2006.

HE C, KLIONSKY DJ: Regulation mechanisms and signaling pathways of autophagy. Annu Rev Genet 43: 67-93, 2009.

HWANG J, LEE S, LEE JT, KWON TK, KIM DR, KIM H, PARK HC, SUK K: Gangliosides induce autophagic cell death in astrocytes. Br J Pharmacol 159: 586-603, 2010.

INOUE H, NOJIMA H, OKAYAMA H: High efficiency transformation of Escherichia coli with plasmids. Gene 96: 23-28, 1990.

JAGDEV SP, COLEMAN RE, SHIPMAN CM, ROSTAMI-H A, CROUCHER PI: The bisphosphonate, zoledronic acid, induces apoptosis of breast cancer cells: evidence for synergy with paclitaxel. Br J Cancer 84: 11261134, 2001. 
JU JS, WEIHL CC: Inclusion body myopathy, Paget's disease of the bone and fronto-temporal dementia: a disorder of autophagy. Hum Mol Genet 19: R38-R45, 2010.

KLIONSKY DJ, ABELIOVICH H, AGOSTINIS P, AGRAWAL DK, ALIEV G, ASKEW DS, BABA M, BAEHRECKE EH, BAHR BA, BALLABIO A: Guidelines for the use and interpretation of assays for monitoring autophagy in higher eukaryotes. Autophagy 4: 151-175, 2008.

KOÇER G, NAZIROĞLU M, ÇELIK Ö, ÖNAL L, ÖZÇELIK D, KOÇER M, SÖNMEZ TT: Basic fibroblast growth factor attenuates bisphosphonate-induced oxidative injury but decreases zinc and copper levels in oral epithelium of rat. Biol Trace Elem Res 153: 251-256, 2013.

LEVINE B, KLIONSKY DJ: Development by self-digestion: molecular mechanisms and biological functions of autophagy. Dev Cell 6: 463-477, 2004.

LIN JF, LIN YC, LIN YH, TSAI TF, CHOU KY, CHEN HE, HWANG TIS: Zoledronic acid induces autophagic cell death in human prostate cancer cells. J Urol 185: 1490-1496, 2011.

MITROFAN LM, PELKONEN J, MÖNKKÖNEN J: The level of ATP analog and isopentenyl pyrophosphate correlates with zoledronic acid-induced apoptosis in cancer cells in vitro. Bone 45: 1153-1160, 2009.

MITROFAN LM, CASTELLS FB, PELKONEN J, MÖNKKÖNEN J: Lysosomal-mitochondrial axis in zoledronic acid-induced apoptosis in human follicular lymphoma cells. J Biol Chem 285: 1967-1979, 2010.

MIZUSHIMA N, YOSHIMORI T: How to interpret LC3 immunoblotting. Autophagy 3: 542-545, 2007.

MÖNKKÖNEN H, AURIOLA S, LEHENKARI P, KELLINSALMI M, HASSINEN IE, VEPSÄLÄINEN J, MÖNKKÖNEN J: A new endogenous ATP analog (ApppI) inhibits the mitochondrial adenine nucleotide translocase (ANT) and is responsible for the apoptosis induced by nitrogen-containing bisphosphonates. $\mathrm{Br} \mathrm{J}$ Pharmacol 147: 437-445, 2006.

MÖNKKÖNEN H, OTTEWELL PD, KUOKKANEN J, MÖNKKÖNEN J, AURIOLA S, HOLEN I: Zoledronic acidinduced IPP/ApppI production in vivo. Life Sci 81: 1066-1070, 2007.

MÖNKKÖNEN H, KUOKKANEN J, HOLEN I, EVANS A, LEFLEY DV, JAUHIAINEN M, AURIOLA S, MÖNKKÖNEN J: Bisphosphonate-induced ATP analog formation and its effect on inhibition of cancer cell growth. Anticancer Drugs 19: 391-399, 2008.

MORICEAU G, ORY B, MITROFAN L, RIGANTI C, BLANCHARD F, BRION R, CHARRIER C, BATTAGLIA S, PILET P, DENIS MG, SHULTZ LD, MÖNKKÖNEN J, RÉDINI F, HEYMANN D: Zoledronic acid potentiates mTOR inhibition and abolishes the resistance of osteosarcoma cells to RAD001 (everolimus): pivotal role of the prenylation process. Cancer Res 70: 10329-10339, 2010.

OTTEWELL PD, WOODWARD JK, LEFLEY DV, EVANS CA, COLEMAN RE, HOLEN I: Anticancer mechanisms of doxorubicin and zoledronic acid in breast cancer tumor growth in bone. Mol Cancer Ther 8: 2821-2832, 2009.

PAGLIN S, HOLLISTER T, DELOHERY T, HACKETT N, MCMAHILL M, SPHICAS E, DOMINGO D, YAHALOM J: A novel response of cancer cells to radiation involves autophagy and formation of acidic vesicles. Cancer Res 61: 439-444, 2001.

PAN J, SONG E, CHENG C, LEE MH, YEUNG SC: Farnesyltransferase inhibitors-induced autophagy: Alternative mechanisms? Autophagy 5: 129-131, 2009.

RÄIKKÖNEN J, CROCKETT JC, ROGERS MJ, MÖNKKÖNEN H, AURIOLA S, MÖNKKÖNEN J: Zoledronic acid induces formation of a pro-apoptotic ATP analogue and isopentenyl pyrophosphate in osteoclasts in vivo and in MCF-7 cells in vitro. Br J Pharmacol 157: 427-435, 2009.

ROGERS MJ, CROCKETT JC, COXON FP, MÖNKKÖNEN J: Biochemical and molecular mechanisms of action of bisphosphonates. Bone 49: 34-41, 2011.

SAMBROOK J, FRITSCH EF, MANIATIS T: Molecular Cloning: A Laboratory Manual. Cold Spring Harbor Laboratory Press, New York, 1989, pp 25-28.

SCHERZ-SHOUVAL R, SHVETS E, FASS E, SHORER H, GIL L, ELAZAR Z: Reactive oxygen species are essential for autophagy and specifically regulate the activity of Atg4. EMBO J 26: 1749-1760, 2007.

SHVETS E, FASS E, ELAZAR Z: Utilizing flow cytometry to monitor autophagy in living mammalian cells. Autophagy 4: 621-628, 2008. 
SONNEMANN J, BUMBUL B, BECK JF: Synergistic activity of the histone deacetylase inhibitor suberoylanilide hydroxamic acid and the bisphosphonate zoledronic acid against prostate cancer cells in vitro. Mol Cancer Ther 6: 2976-2984, 2007.

TAKEUCHI H, KONDO Y, FUJIWARA K, KANZAWA T, AOKI H, MILLS GB, KONDO S: Synergistic augmentation of rapamycin-induced autophagy in malignant glioma cells by phosphatidylinositol 3kinase/protein kinase B inhibitors. Cancer Res 65: 3336-3346, 2005.

THOMPSON K, ROGERS M: The molecular mechanisms of action of bisphosphonates. Clin Rev Bone Miner Metab 5 : 130-144, 2007.

VESA J, SU H, WATTS GD, KRAUSE S, WALTER MC, MARTIN B, SMITH C, WALLACE DC, KIMONIS VE: Valosin containing protein associated inclusion body myopathy: abnormal vacuolization, autophagy and cell fusion in myoblasts. Neuromuscul Disord 19: 766-772, 2009.

WASKO BM, DUDAKOVIC A, HOHL RJ: Bisphosphonates induce autophagy by depleting geranylgeranyl diphosphate. Pharmacol Exp Ther 337: 540-546, 2011.

YAMAMOTO A, TAGAWA Y, YOSHIMORI T, MORIYAMA Y, MASAKI R, TASHIRO Y: Bafilomycin A 1 prevents maturation of autophagic vacuoles by inhibiting fusion between autophagosomes and lysosomes in rat hepatoma cell line, H-4-II-E cells. Cell Struct Funct 23: 33-42, 1998.

ZHUANG W, QIN Z, LIANG Z: The role of autophagy in sensitizing malignant glioma cells to radiation therapy. Acta Biochim Biophys Sin 41: 341-351, 2009. 